\title{
EMPOWERING PERSONS LIVING WITH DISABILITIES VIA INCLUSIVE PRACTICES IN ORGANIZED SECTORS - LEARNINGS FROM DEVELOPED NATIONS
}

\author{
Herratdeep Singh ${ }^{1 *}$, Prerana Pandia ${ }^{1}$ and Rajesh Nair ${ }^{1}$ \\ ${ }^{1}$ Indian Institute of Public Health Delhi, India
}

\begin{abstract}
Issue of disability has figured on International Human Rights agenda in on several occasions. The existence of disability often results in decrease in social and economic well-being. Understanding the numbers of people with disabilities and their circumstances can improve efforts to remove disabling barriers and provide services to allow people with disabilities to participate. Present research has analyzed the practices in developed nations under organized sectors to how they empower the people living with disabilities to get their rightful space in the areas of work and education. Present research has systematically reviewed research papers, reports (years 2001to 2017), case studies, epidemiological studies via online database 'PubMed', 'Google Scholar' and 'Web of Science'. The good practices, lessons, barriers have been identified to advocate such good practices in developing nations. There is lot to learn from countries like Switzerland, Norway, Canada etc., which have the highest rates of employment for persons with disabilities. The participation of people with disabilities is important for promoting human dignity, social cohesion and accommodating the disabled working age population. There are ample of good practices in developed nations which we can adopt to make the work environment most inclusive, equitable and enabling for people living with disabilities.
\end{abstract}

Keywords: Inclusion, Disabled persons, Employment, Education

\section{Introduction}

Case Definition- Disability- A disability is defined in the Equality Act 2010 as 'a physical or mental impairment which has a substantial and long-term adverse effect on someone's ability to carry out normal dayto-day activities'.

Disability is a human condition. At any point of life, everyone would have witnessed one or the other form of disabilities and as one survives to older ages, increasing issues with functioning are witnessed. Many of the joint families have at least one member with disability and the others who are not disabled assist disabled member in day to day activities. As demographic transition is taking place and people are living longer, the issue of disability would be seen as a major challenge to deal in coming times. There is a change in response to disability since the 1970s, largely prompted by the self-organization of disabled people and by the increasing tendency to see disability as a human rights issue. In the past, people with disabilities were largely been kept segregated from others in special schools and residential institutions. There is a paradigm shift as now policies are more towards community and educational inclusion, and medically-focused solutions have lead to more interactive approaches as people are disabled by environmental factors as well as by their bodies. United Nations Standard Rules on the Equalization of Opportunities of Persons with Disabilities - have incorporated the human rights of people with disabilities, culminating in 2006 with the adoption of the United Nations Convention on the Rights of Persons with Disabilities (CRPD)(“report.pdf," n.d.). A WHO World report on disability provides evidence to 
facilitate implementation of the CRPD. This report documents conditions of persons with disabilities across the world and explore the measures to increase their participation in society, ranging from health and rehabilitation to education and employment. Disability is complex, dynamic, multidimensional, and contested. Disability is the umbrella term for impairments, activity limitations and participation restrictions, referring to the negative aspects of the interaction between an individual (with a health condition) and that individual's contextual factors (environmental and personal factors). Disability is a developmental issue as it has a two way linkage with poverty as disability may lead to poverty and poverty may lead to disability. There is growing empirical evidence from across the world shows that people with disabilities and their families are likely to face social and economic disadvantages than those without disabilities. Onset of disability may lead to worsening of social and economic well being. Children affected with disabilities have less chances of attending school, therefore they witness limited opportunities for human capital formation and witness reduced employment opportunities and there is fall in their productivity in adulthood. The chances of employment are very dull for persons with disabilities. It is also seen that employment and incomes falls with increase in degree of disability.("report.pdf," n.d.)

\section{Methodology}

Present research has systematically reviewed research papers, reports (years 2001to 2017), case studies, epidemiological studies via online database 'PubMed', 'Google Scholar' and 'Web of Science'. The good practices, lessons, barriers have been identified to advocate such good practices in developing nations. The literature review was conducted using various keywords like Inclusion, Disabled persons, Employment and Education. The research was done in two different steps. At the very first step the research was conducted looking at inclusion practices for disabled persons in the employment sector and further we proceeded with involving inclusion practices at levels of education too. Then we also looked for several papers, reports and studies by conducting a desk review using 'Google Scholar' search engine, where we were able to extract some guiding manuals provided by various country unions or several organizations regarding the provision of enabling environment to the people with disabilities at workplace and also issues regarding the employment of such individuals at the first place. We were also successful in extracting the world report on disability published by WHO and World Bank collectively and also a report published by International Labour Organization which provides codes of practice on managing disability at workplace. The inclusion criterias of our review were the studies which were specifically addressing the empowerment of disabled individuals through inclusion of them in organized sector, also all the studies conducted in developed nations were include which were published in English language. Articles which were not satisfying all the inclusion criterias despite of satisfying one or two of them were excluded. 


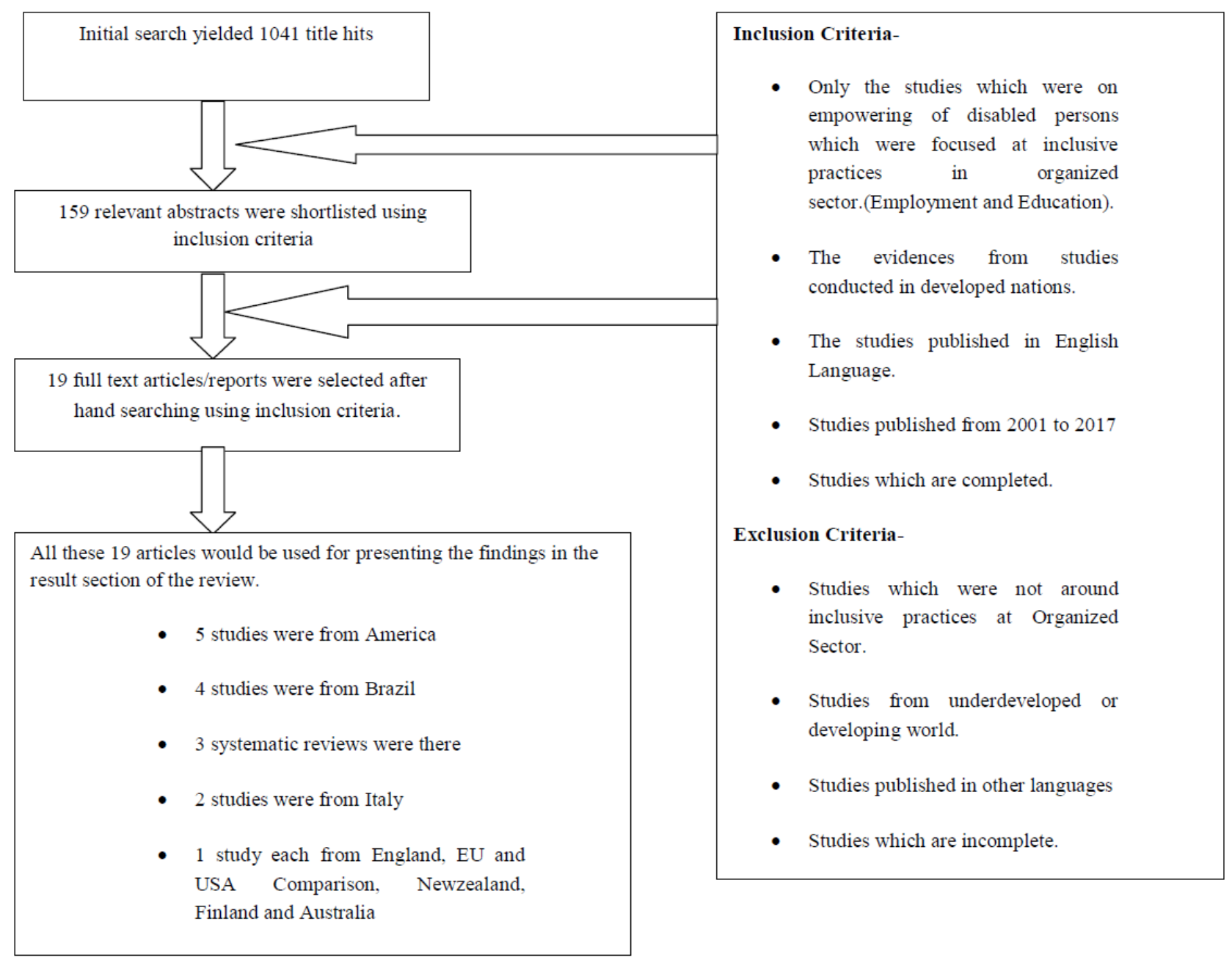

Figure 1: Flow Chart of Search Strategy

\section{Results/Findings:}

\section{As per World Report on Disability:-}

In Article 27 the United Nations Convention on the Rights of Persons with Disabilities (CRPD) "recognizes the right of persons with disabilities to work, on an equal basis with others; this includes the opportunity to gain a living by work freely chosen or accepted in a labour market and work environment that is open, inclusive and accessible to persons with disabilities". Also, the CRPD prevents every form of discrimination in employment; it also promotes access to vocational training, promotes self-employment opportunities for disabled, and asks for reasonable accommodation in the workplace along with other provisions. There are various labour market imperfections (discrimination and prejudice) and to overcome them and encourage the employment of individuals with disabilities, many of the countries have strict laws prohibiting discrimination on the basis of disability. Implementing such laws is expected to positively impact access to the formal economy and have many social benefits. Many countries provide quotas, which are aimed at increasing the employment opportunities for disabled persons. The most important measure is to change attitudes at workplace.

Importance of participation of disabled persons in labour force-

Maximising Human Resources- Involving persons with disabilities not only betters individual well being but also improve national capital. 
Promoting Human Dignity and Social Cohesion- Providing employment to disabled persons will provide personal as well as social benefits, which adds to a feeling of dignity and social cohesion.

Accommodating the increasing numbers of people with disabilities in the working age population- This becomes most important when we are expecting the rise in prevalence of disability in coming decades as employing these individuals will increase our workforce with also benefitting disabled persons along with nations.

Employment Rates- It is an indicator of labour market status of persons living with disabilities. Analysis of the World Health Survey results for 51 countries gives employment rates of $52.8 \%$ for men with disability and $19.6 \%$ for women with disability, compared with $64.9 \%$ for non-disabled men, and $29.9 \%$ for non-disabled women. The employment rates for people with different disabilities are different with the lowest among the individuals who have mental health issues and intellectual impairments.

People with disabilities need flexibility in the timings and several other aspects of work - to give them proper time to get ready for work, to travel to and from work, and to manage their health concerns.("report.pdf," n.d.)

Addressing the barriers to work and employment:-

Laws and Regulations- Anti-discrimination laws makes it illegal to take decisions about individual's employment on the basis of his/her disability, as in Canada (1986, 1995), Australia (1992), United States (1990).and the New Zealand (1993). Examples of reasonable accommodations include to ensure that recruitment and selection procedures are accessible, adaptable working environment, modified working times and other arrangements, and providing screen-reader software and other technology assistance.

\section{Affirmative action-}

Anti-discrimination measures call for "affirmative action" in disabled individual employment. In 2000 the Council of the European Union called its member states to introduce policies on the employment of people with disabilities by 2006. In response to this meeting, Portugal, for instance came with a National Action Plan that included affirmative action to employ persons living with disabilities.

Quotas- It was assumed that if quotas would not be provided to the disabled persons, there applications would always be turned down by the employers because of various fears. Germany have 5\% quota for those persons who are severely disabled in the firms employing more than 20 workers.

Incentives for employers- It is believed that if employment would be provided to the disabled persons, the cost has to be bear by the employers. So to overcome these obstacles, it was thought of incentivizing the employers. Examples are, Vocational rehabilitation agency of USA provided funding for workplace related accommodations and

Department of Employment and Workplace Relations of Australia funds the Workplace Modifications Scheme, which provides up to $\mathrm{A} \$ 10000$ to accommodate new employees with disabilities.("report.pdf," n.d.)

\section{Vocational rehabilitation and training}

Vocational rehabilitation has a potential to restore and develop the capabilities of people with disabilities so as to increase their participation in competitive markets. For example, in Thailand the Redemptorist Vocational School for the Disabled offers job placement as well as training in computer skills and business management. 


\section{Alternate forms of Training-}

Early interventions- In Australia a project was undertaken in which computer training was provided to people with recent spinal cord injuries when they are still in hospital has led to increased rates of return to further education and training or work.

Mentoring. In the United States collaboration between the government and private enterprise provides summer internships to hundreds of young people with disabilities.("report.pdf," n.d.)

\section{Inclusion of workers with hearing loss: Guidelines for work practice professionals-}

- They should carry out a scan of services and resources needed by workers with hearing loss and employers.

- Identifying hearing accessibility issues, through use of Universal Design of Hearing Guide.

- Increase awareness around hearing demands at workplace work using various tools.

- Identify workers that are at risk of work loss.

- Educate organizations on compliance with legislations or policies around inclusion practices. (Shaw et al., 2013)

\section{The New Freedom Initiative- Self Determination and Career Development}

On February, 2001 President Bush of United States of America announced this initiative. This step was taken in order to ensure that people of America with disabilities have opportunity develop skills and participation in productive work. The goals of initiative were increase the access to assistive and universally designed technologies, providing educational opportunities and inclusion of persons living with disabilities into workforce. According to a study done by Wehmeyer and Schwartz (1995), the students who are given self determination skills which involves self awareness, self advocacy and self efficacy/self confidence perform better after school as compared to those who did not receive this training.

The School-to Work Opportunities Act of 1994 and IDEA of 1997 promote quality transition programs and services which will enable students to choose career and life choices that will increase their employment outcomes. (Izzo et al.)

Wehmeyer, Palmer, Agran, Mithaug, and Martin (2000) have developed and studied a model "The Self-Directed Learning Model of Instruction" to help students with disabilities in planning and directing their learning. This model involves problem based approach that involves three phase process- (1) What is my goal?, (2) What is my plan?, and (3) What have I learned? (Izzo et al.)

The Philadelphia's School-to-Careers program reported that students who were part of work-based learning had higher Grade Point Averages (GPA) than students involved. (Izzo et al.)

The American Occupational Therapy Association (AOTA) supports the Americans with Disabilities Act of 1990 (ADA; Public Law 101-330) a legislation passed by Congress in 1990 to ensure civil rights protection and the inclusion of persons with disabilities into society.

\section{Places of Public Accommodation}

Occupational therapy education enables practitioners to understand how various attitudinal and environmental barriers affect a person's potential to function in the community and pursue an occupation. ADA's Title3 talks of removal of environmental barriers and improve access in both public and private sector.

Occupational therapy practitioners' knowledge of accessibility guidelines (ADAAG and UFAS) provides framework for relevant recommendations to create reasonable and necessary accessible environments. 


\section{Employment}

Under the employment provisions of the ADA, the occupational therapy person maintains a major role in this. The Equal Employment Opportunity Commission (EEOC), the federal agency charged with administering the ADA, recognized occupational therapy as one of the professions eligible to provide technical assistance for ADA compliance. Occupational therapists are provided with training to determine the several skills needed for a worker's functional performance. Occupational therapy practitioners play a vital role in removing the myths, misconceptions and fears about disabled individuals in the workplace. They have contribution in sensitizing co workers and supervisors working with disabled persons to interact in non-discriminatory manner. (AOTA, 1999). Occupational therapist help disabled persons to prepare for employment by providing them with vocational trainings. The clients are educated on how to face the interviews for employment and how to ask for accommodations at workplace from the employer.("Occupational Therapy and The Americans With Disabilities Act (ADA) | American Journal of Occupational Therapy,” n.d.)

It is very much important to build a culture of inclusion. Rush University Medical University of USA upheld disabled rights. RUMC has shown complete commitment in recruiting and retaining employees with disabilities and also the students with disabilities playing their role as a healthcare professions university. RUMC partnered with Professional Assistance Centre for Education program at National Lewis University, which was a 2 year program to meet demands of young adults with learning disabilities by providing job training internships. RUMC also ensures that healthcare professions accept people with disabilities. In the recognition of the above mentioned efforts RUMC was bestowed with prestigious awards. RUMC is mentioned as setting the standard of excellence in America.(Ailey et al., 2015)

How an Employee should address discrimination complaints-

- If an employer comes to know that discrimination or victimisation is being practiced because of someone's disability, ideally they should not wait for a complaint to be launched.

- An employee should be given the choice to discuss the matter whether formally or informally,

Taking a 'Positive Action'-

Under the Equality Act, an employer can take 'positive action' to help employees or job applicants it thinks:

- Are disadvantaged because of their disability, and/or;

- Representation is hampered in the organisation, or

- Have disability specific need.

- An employer can take proportionate steps to remove any barriers or disadvantages;

- $\quad$ Provide support to encourage employees with disabilities.

Employee's wish for confidentiality-

An employee's disability should be kept confidential by the employer unless the employee agrees to share the information. The employer should:

- talk to employees about the things they want to share with their colleagues, and

- who all colleagues would be told about their condition and who will share this information.

Considerations for life threatening conditions may include-

- Managers should be trained to handle circumstances where an employee has a potential or actual lifethreatening condition

- Mannerism of interaction during the off work period would be pre decided.

- The employee needing time off for treatment and/or counselling. 
Unacceptable Terminology and Behaviour-

- Rule of thumb is to avoid using words that have negative connotation.

- An employer should provide trainings to employees around equality about what terminology is acceptable when referring to disability of any person.

Under the Equality Act-

- A job applicant who thinks a prospective employer is acting unlawfully by asking questions about their health can complain to the Equality and Human Rights Commission.

- An applicant can file case of discrimination against the employer if he/she asks unlawful questions regarding their health and then not provided them with employment.

Flexible Working-

- Flexible working might be a 'reasonable adjustment' for an employee with a disability.

- A mandatory condition is that all employees who have worked for their employer continuously for 26 weeks have the right to ask for flexibilities in their work.

- if the request amounted to a 'reasonable adjustment' regarding disability, an employer can't turn down the request.(“Disability_discrim_keypoints_workplace_Nov.pdf," n.d.)

Best Practices In PWD Employment: Global Standards

\section{Legislation-}

- Government of many countries have drafted policies and programs for action on inclusion of persons living with disabilities at workplace.

- In US Workforce Investment Act, 1998 brought placements under 'One Stop Centres' which tries to achieve equal opportunities for disabled persons.

\section{Supportive Environment-}

- In many countries the employment for PWDs (persons with disabilities) is provided under sheltered businesses. Best example is Switzerland which is the country with highest percentage of PWDs employed in the world.

\section{Mentoring and Peer Learning-}

- In many countries, such as US, the mentoring programs are run by government and private owners of companies and NGOs for youth with disabilities to build networking, awareness around career options, build skills and get placed.(American India Foundation-Best Practices in Employment of people with disabilities in the private sector in India)

In Brazil, Several laws have been introduced for the purpose of promoting inclusion in the labour market, the latest was Law No. 8213/91 which, in article 93, states that "a company with one hundred (100) or more employees is required to allocate between two percent (2\%) and five percent $(5 \%)$ of its job openings to or disabled persons, qualified in the following proportions: I - up to 200 employees, 2\%; II - between 201 and 500, 3\%; III - between 501 and 1000, 4\%; IV - from 1001 upwards, 5\%" (Silva et al., 2015)

\section{Acknowledgement}

I would like to acknowledge my mentor Dr. Rajesh Nair, Associate Professor, Indian Institute of Public Health Delhi for encouraging me to participate in national and international conferences and also to undertake and present my research in those conferences. 


\section{References}

Ailey, SH, Brown, P, Friese, TR, Dugan, S, 2015, 'Building a Culture of Inclusion: Disability as Opportunity for Organizational Growth and Improving Patient Care', vol. 46, no. 1, pp. 9-11, DOI: 10.1097/NNA.0000000000000286

Disability discrimination: Key points for the workplace report, viewed on $27^{\text {th }}$ November, 2017. (http://m.acas.org.uk/media/pdf/s/k/Disability_discrim_keypoints_workplace_Nov.pdf)

Izzo, M, Lamb, MP, 'Self-Determination and Career Development: Skills for Successful Transitions to Postsecondary Education and Employment'

Shaw, L, Jennings, MB, Kramer, SE, 2013, 'Work transition tips: Inclusion for workers with hearing loss: Actions for work practice professionals', pp. 205-206, DOI: 10.3233/WOR-131745

Silva, PN, Prais, FG, Silveira, AM, 2015, 'The inclusion of disabled persons in the labour market in Belo Horizonte, Brazil: scenario and perspective', vol. 20, no. 8, pp. 2549-2558, DOI: 10.1590/141381232015208.17802014

World report on disability, 2011, viewed on $25^{\text {th }}$ November, 2017. 